\title{
Molecular genetic diversity and association mapping of morphine content and agronomic traits in Turkish opium poppy (Papaver somniferum) germplasm
}

\author{
Ibrahim Celik • Huseyin Camci • Arzu Kose • \\ Ferda Celikoglu Kosar · Sami Doganlar • Anne Frary
}

Received: 6 January 2016/Accepted: 25 March 2016/Published online: 5 April 2016

(C) Springer Science+Business Media Dordrecht 2016

\begin{abstract}
As the sole plant source of many potent alkaloids, opium poppy (Papaver somniferum L.) is an important medicinal crop. Nevertheless, few studies have characterized opium poppy germplasm with cropspecific molecular markers. Because Turkey is a diversity center for opium poppy, Turkish germplasm is a valuable genetic resource for association mapping studies aimed at identifying QTLs controlling morphine content and agronomic traits. In this study, the morphological diversity and molecular diversity of 103 Turkish opium poppy landraces and 15 cultivars were analyzed. Potentially useful morphological variation was observed for morphine content, plant height, and capsule index. However, the landraces exhibited limited breeding potential for stigma number, and seed and straw yields. Both morphological and molecular analyses showed distinct clustering of cultivars and landraces. In addition, a total of 164 SSR and 367 AFLP polymorphic loci were applied to
\end{abstract}

Electronic supplementary material The online version of this article (doi:10.1007/s11032-016-0469-8) contains supplementary material, which is available to authorized users.

I. Celik $\cdot$ S. Doganlar $\cdot$ A. Frary $(\bowtie)$

Department of Molecular Biology and Genetics, Izmir Institute of Technology, Urla, Izmir 35430, Turkey

e-mail: annefrary@iyte.edu.tr

H. Camci · A. Kose · F. C. Kosar

Anatolia Agricultural Research Institute (AARI),

Eskisehir, Turkey an opium poppy association mapping panel composed of 95 opium poppy landraces which were grown for two seasons. One SSR and three AFLP loci were found to be significantly associated with morphine content $\left(P<0.01\right.$ and LD value $\left.\left(r^{2}\right)=0.10-0.32\right)$, and six SSR and 14 AFLP loci were significantly associated with five agronomic traits (plant height, stigma number, capsule index, and seed and straw yields) $\left(P<0.01\right.$ and LD value $\left.\left(r^{2}\right)=0.08-0.35\right)$. This is the first report of association mapping in this crop. The identified markers provide initial information for marker-assisted selection of important traits in opium poppy breeding.

Keywords AFLP · Microsatellites · Morphine content · Papaver somniferum $\cdot$ Seed and straw yields

\section{Introduction}

Opium poppy (Papaver somniferum L.) is a major source of many pharmaceutically valuable alkaloids such as morphine, codeine, and noscapine (Facchini and De Luca 2008). Because of its rich alkaloid content, opium poppy is an important medicinal crop for many poppy-growing countries such as Turkey, India, and Bulgaria. Turkey is a historically significant opium poppy producer with the Irano-Anatolian region accepted as the center of origin of this crop (Turkish Soil Product Office 2009; Tétényi 1997). Although half 
of the legal opium poppy production area in the world lies within Turkey (Turkish Soil Product Office 2009), the country ranks only third in morphine production $(18 \%)$ due to the prevalence of low morphine cultivars. Efforts to improve alkaloid content have been hampered by a lack of information about the genetic diversity and breeding potential of Turkish germplasm (Gumuscu and Arslan 2008) as well as the difficulty of breeding for biochemical traits.

In addition to its medicinal importance, opium poppy is economically significant as the world requires approximately 400 tons per year with an estimated value of $\$ 320$ million (Turkish Soil Product Office 2014). Despite the crops' value, few molecular markerbased genetic diversity studies have been published and most of these have used nonspecific marker systems such as AFLP, RAPD, and ISSR (Acharya and Sharma 2009; Dittbrenner et al. 2008; Parmaksiz and Ozcan 2011; Saunders et al. 2001). Recently, opium poppy-specific EST and genomic SSR markers were developed and shown to be useful for diversity assessment in the crop and transferable to other poppy species (Selale et al. 2013; Celik et al. 2014). Although Turkish germplasm has not been molecularly characterized to date, landraces and cultivars have been examined for their morphological trait variation $(\mathrm{Gu}-$ muscu and Arslan 1999; Arslan et al. 2000; Gumuscu et al. 2008). The largest study analyzed morphine content of 353 opium poppy accessions (Arslan et al. 2000). In other work, morphine content and agronomic traits (flowering period, seed yield, capsule yield, and capsule number) of 20 opium poppy cultivars were analyzed (Gumuscu and Arslan 1999). The only other published research with Turkish opium poppy reported the morphine, thebaine, codeine, papaverine, and noscapine contents of 99 lines (Gumuscu et al. 2008). Thus, there is a dearth of research examining both molecular and morphological diversity in this valuable crop.

Marker-assisted selection (MAS) is a widely used method that facilitates crop selection and breeding. MAS must be integrated into opium poppy breeding for efficient improvement of complex biochemical and agronomic traits such as seed yield and straw yield. The first requirement for implementation of MAS in breeding is identification of quantitative trait loci (QTLs) for the characters of interest and linked molecular markers (Collard et al. 2005); however, to date, no such work has been done toward the adoption of MAS in opium poppy. Association mapping (AM), also called linkage disequilibrium or LD mapping, is a powerful strategy for identification of QTLs in plant genomes (Zhu et al. 2008). AM has higher resolution than mapping based on biparental populations because it takes advantage of recombination events that have accumulated during evolution and the resulting greater allelic diversity in natural plant germplasm (Gómez et al. 2011). Although AM has been extensively applied in major crop species, relatively little work has been done in nonmodel plants such as poppy. Some exceptions include work in teosinte, oat, peanut, loblolly pine, and sesame that used LD to identify significant associations between molecular markers and agronomic traits (Weber et al. 2008; Achleitner et al. 2008; Wang et al. 2011; Eckert et al. 2012; Wei et al. 2013). The main problem in AM is the occurrence of false-positive associations due to population structure and the relatedness of individuals. Such factors are determined by the crop's mating system and breeding history (Stich et al. 2005; Semagn et al. 2010). Falsepositive associations may be detected in opium poppy because it is self-pollinating with a low but significant amount of outcrossing (10-37\%) in the presence of insects (Patra et al. 1992). Detection of false-positive associations can be corrected by using models such as the general linear model (GLM) and mixed linear model (MLM) which take into account population structure $(\mathrm{Q})$, kindship matrix $(\mathrm{K})$, and principal component (PC) information (Bradbury et al. 2007; Price et al. 2006; Yu et al. 2006). The association model with the best fit to the experimental data will have the lowest false discovery rate (FDR) (Akhatar and Banga 2015).

The first aim of the current research was to assess genetic diversity in 103 Turkish opium poppy landraces and 15 certified cultivars using both morphological traits and the aforementioned opium poppyspecific EST and genomic SSR markers. The characterization of Turkish germplasm will enable the informed selection of parental lines for the development of opium poppy cultivars with improved alkaloid content and seed yield. The second aim of the research was to identify QTLs for morphine content and agronomic traits using AM. To achieve this, 95 randomly chosen Turkish landraces characterized for morphine content and agronomic traits were genotyped with SSR and AFLP markers to identify loci significantly associated with the traits. This is the first 
study to reveal the molecular genetic and morphological diversity and population structure of Turkey's opium poppy genetic resources and to identify QTLs associated with morphine content and agronomic traits by AM.

\section{Materials and methods}

\section{Plant material}

For morphological and molecular genetic diversity analysis, 103 opium poppy landraces collected from eight cities (Afyon, Burdur, Usak, Eskisehir, Isparta, Denizli, Kutahya, and Sivas) in the central Anatolian and southern Aegean regions of Turkey were obtained from the Anatolia Agricultural Research Institute (AARI) (Table S1). In addition, eight and seven cultivars were obtained from the Turkish Soil Product Office (TMO) and AARI, respectively. TMO and AARI are responsible for all opium poppy breeding in Turkey. P. umbonatum was used as out-group and was obtained from the U.S. Department of Agriculture, Agricultural Research Service Plant Germplasm Inspection Station, Beltsville MD, USA. For AM, 95 accessions were randomly selected from the 103 landraces used for diversity analysis.

\section{Morphological trait analysis}

The opium poppy landraces were grown in the field in Eskisehir during the 2011 and 2012 growing seasons. Plants were in $5 \mathrm{~m}$ long, three-row plots with a row spacing of $0.45 \mathrm{~cm}$. The plants were fertilized with $6 \mathrm{~kg} \mathrm{ha}^{-1}$ phosphorus and $6 \mathrm{~kg} \mathrm{ha}^{-1}$ nitrogen. Morphine content of landraces was measured by HPLC (high-performance liquid chromatography). A total of $50 \mathrm{~g}$ poppy straw (capsule without seed) bulked from several plants per accession were ground with activated acidic $\mathrm{Al}_{2} \mathrm{O}_{3}$ for $30 \mathrm{~min}$. The filtered solution was used for HPLC analysis with mobile phase containing $1 \%$ TFA in water-acetonitrile-methanol $(46: 40: 14, \mathrm{v} / \mathrm{v})$. These results were used to calculate the percentage of morphine content in straw.

Morphological traits were measured on 10 randomly selected plants of each accession and included: height $(\mathrm{cm})$, stigma number, capsule index, and seed and straw yields. Capsule index was calculated by dividing capsule height by capsule diameter. Seed and straw yields were measured as gram per plot and then converted to $\mathrm{kg}$ per hectare.

The 2-year data were averaged for each trait. In addition, means and coefficients of variation for cultivars and landraces were calculated separately for comparison. Principal component analysis (PCA) was performed with DARwin (Perrier and Jacquemoud-Collet 2006; and PASW software (Norusis 2010). Basic statistics such as correlation analysis between traits and paired sample Student's $t$ tests were performed using PASW software.

Molecular marker analysis

Seeds of each accession were planted in seedling plates in standard soil mix. Plants were grown in the greenhouse $\left(24-25{ }^{\circ} \mathrm{C}\right.$, approximately $33 \%$ humidity). Total genomic DNA was isolated from leaf tissue bulked from ten plants per accession using a CTAB method (Doyle and Doyle 1990). For molecular genetic diversity analysis, 13 EST-SSR markers (Selale et al. 2013) and 33 genomic SSR markers (Celik et al. 2014) were tested in the 118 P. somniferum accessions and $P$. umbonatum according to the amplification protocols in the respective publications.

Both SSR and AFLP markers were assayed on the AM panel. In addition to the SSRs described above, a further 34 SSR markers (Selale et al. 2013; Celik et al. 2014) were tested on the panel to increase genome coverage. Thus, a total of 80 SSR markers were used which consisted of 14 EST-SSR and 66 genomic SSR markers. Amplified PCR fragments were separated using a Fragment Analyzer ${ }^{\mathrm{TM}}$ (Advanced Analytical Technologies, Inc.) with a DNF-900 dsDNA Reagent Kit (Advanced Analytical) and appropriate method (sample injection voltage $7.5 \mathrm{kV}$ for $15 \mathrm{~s}$, separation voltage $8 \mathrm{kV}$ for $80 \mathrm{~min}$ ).

AFLP markers were also used in AM to increase genome coverage. For AFLP analysis, 10 primer combinations $\quad(\mathrm{E}-\mathrm{ACT}+\mathrm{M}-\mathrm{CAG}, \quad \mathrm{E}-\mathrm{AAC}+\mathrm{M}-\mathrm{CTT}$, $\mathrm{E}-\mathrm{AAC}+\mathrm{M}-\mathrm{CTC}, \quad \mathrm{E}-\mathrm{ACG}+\mathrm{M}-\mathrm{CAA}, \quad \mathrm{E}-\mathrm{ACC}+$ M-CAC, E-AGC + M-CTA, E-ACA + M-CTG, $\mathrm{E}-\mathrm{ACC}+\mathrm{M}-\mathrm{CAG}, \mathrm{E}-\mathrm{ACA}+\mathrm{M}-\mathrm{CAG}$, and E-AGG + $\mathrm{M}-\mathrm{CAT}$ ) were used in selective amplification using the AFLP Core Reagent and AFLP Starter Primer Kits from Invitrogen (Carlsbad, CA) according to the manufacturer's protocol. AFLP primers were labeled with blue fluorescent dye for separation in the CEQ 8800 Sequencer (Beckman-Coulter, Fullerton, 
CA). The default Frag 4 separation method was used: capillary temperature $50{ }^{\circ} \mathrm{C}$, denaturation temperature $90{ }^{\circ} \mathrm{C}$ for $120 \mathrm{~s}$, injection voltage $2.0 \mathrm{kV}$ for $30 \mathrm{~s}$, and separation voltage of $4.8 \mathrm{kV}$ for $60.0 \mathrm{~min}$.

Population structure and molecular genetic diversity analysis

Amplified SSR loci were scored as present (1) or absent (0). Rare PCR fragments (those that occurred at less than $10 \%$ frequency) were potentially unreliable and excluded from analysis. The binary data generated by EST and genomic SSR markers were analyzed for population structure with the computer program Structure (Pritchard et al. 2000a) which uses a model-based Bayesian method to assign accessions to subpopulations. To find the best model representing population structure, the program performs calculations using different models $(K=1-10$, where $K=$ number of subpopulations) after 50,000 burn-in cycles. Each model was tested 20 times with 100,000 iterations per $\mathrm{K}$. The population structure results were analyzed with the Structure Harvester program (Dent and Bridgett 2012) to find the best model with the highest $\Delta \mathrm{K}$ value. A threshold of $\geq 0.80$ inferred ancestry was used to assign accessions to subpopulation clusters. Accessions that did not meet this threshold value were considered to be admixed. For hierarchical clustering, a dissimilarity matrix generated using the Dice coefficient was used to construct a dendrogram with the unweighted neighbor-joining method as implemented by the DARwin computer program (Perrier and Jacquemoud-Collet 2006). The correlation between the dissimilarity matrix and the dendrogram was calculated using a Mantel test as provided in the DARwin computer program.

\section{Association mapping}

The binary data generated for the SSR and AFLP markers assayed on the panel of 93 poppy accessions were used for AM of morphine content and agronomic traits using the GLM and MLM models of TASSEL v2.1 (Trait Analysis by aSSociation, Evolution and Linkage software) software (Bradbury et al. 2007). Linkage disequilibrium (LD) values ( $r^{2}$ and $P$ values) between SSR and AFLP loci were calculated using TASSEL v2.1 software. Different models were tested to determine the model with the best fit for AM analysis. Analysis was first performed using the GLM model without any correction. Then, the GLM model was corrected with the Q-matrix of population structure [GLM (Q)], principal components (PCs) [GLM (PC)], and both Q and PC [GLM (Q + PC)]. Similarly, the MLM model corrected with kindship matrix (K) [MLM (K)] was used and further corrected with the Q-matrix [MLM $(\mathrm{K}+\mathrm{Q})$ ], principal components [MLM $(\mathrm{K}+\mathrm{PC})]$, and both [MLM $(\mathrm{K}+\mathrm{Q}+\mathrm{PC})]$ (Table S2). The Q-matrix generated at $K=2$ (subgroup number $=2$ ) was used as covariate. Principal components (PCs) were calculated in TASSEL software. To determine the best model, the $P$ values generated by the eight models were analyzed with QVALUE (Storey 2002) software using a false discovery rate (FDR) of 0.05 (Storey and Tibshirani 2003). Bootstrap analysis was performed to calculate $\pi 0(\%)$ which indicates the probability that a given hypothesis is truly null, and $\pi 1(\%)(100-\pi 0(\%))$ which represents the probability of significant results. The model with the highest $\pi 1$ value was accepted as the one with the best fit, and its results are reported herein. Marker trait associations with $P$ values lower than 0.01 were selected as significant associations.

\section{Results}

Morphological trait diversity

A total of 103 opium poppy landraces and 15 cultivars were analyzed for morphine content and five quantitative traits: plant height, stigma number, capsule index, and straw and seed yields. Germplasm and cultivars were analyzed separately to assess the breeding potential of the landraces (Table 1). The cultivars had nearly twofold higher mean morphine content $(0.84 \%)$ than the landraces $(0.43 \%)$. Cultivars Ofis 3 , Ofis 4 , and Ofis 8 had the highest morphine content with more than $1.1 \%$ morphine for each. Cultivar Anayurt had the lowest morphine content with only $0.55 \%$. Only $11 \%$ of the landraces had higher morphine content than Anayurt including accession 116 which had the highest morphine content $(0.8 \%)$ among the landraces. Morphine content did not show correlation with any of the morphological traits.

Plant height varied more in the cultivars $(\mathrm{CV}=$ $14 \%)$ than in the landraces $(\mathrm{CV}=5 \%)$ with 71 and $22 \mathrm{~cm}$ ranges for cultivars and landraces, respectively. 
Table 1 Morphine content and morphological traits for the opium poppy landraces and cultivars

\begin{tabular}{|c|c|c|c|c|c|c|c|c|}
\hline \multirow[t]{2}{*}{ Trait } & \multicolumn{4}{|l|}{ Cultivars } & \multicolumn{4}{|l|}{ Landraces } \\
\hline & Mean $\pm \mathrm{SE}$ & $\mathrm{CV}(\%)$ & Range & Range var. & Mean $\pm \mathrm{SE}$ & $\mathrm{CV}(\%)$ & Range & Range var. \\
\hline Morphine content (\%) & $0.84 \pm 0.06$ & 26 & $0.55-1.35$ & 0.8 & $0.43 \pm 0.01$ & 21 & $0.24-0.80$ & 0.56 \\
\hline Plant height (cm) & $117.5 \pm 4.4$ & 14 & $89.0-160.0$ & 71 & $101.7 \pm 0.5$ & 5 & $89.5-111.5$ & 22 \\
\hline Stigma number & $4.5 \pm 0.4$ & 36 & $2.0-8.0$ & 6 & $4.8 \pm 0.1$ & 24 & $2.8-8.5$ & 5.7 \\
\hline Capsule index & $1.08 \pm 0.06$ & 20 & $0.43-1.46$ & 1.03 & $0.95 \pm 0.01$ & 9 & $0.55-1.12$ & 0.57 \\
\hline Seed yield $\left(\mathrm{kg} \mathrm{ha}^{-1}\right)$ & $132.8 \pm 4.2$ & 12 & $110.0-160.0$ & 50 & $100.7 \pm 1.4$ & 14 & $66.5-133.5$ & 67 \\
\hline Straw yield $\left(\mathrm{kg} \mathrm{ha}^{-1}\right)$ & $127.8 \pm 3.8$ & 11 & $109.0-160.0$ & 51 & $76.5 \pm 1.2$ & 17 & $53.0-105.0$ & 52 \\
\hline
\end{tabular}

On average, cultivars $(117.5 \mathrm{~cm})$ were taller than landraces $(101.7 \mathrm{~cm})$. Accessions 14, 86, and 88 were tallest among the landraces but were still shorter than the cultivar mean. Plant height showed low correlation with seed and straw yields $(r=0.22, r=0.32$, respectively).

Variation for stigma number was similar for both cultivars and landraces with two to eight stigmas per flower. Mean stigma number was also similar for cultivars and landraces. Capsule index indicates capsule shape with perfectly round capsules having an index of 1.0. Capsule index for cultivars (1.08) was slightly higher than for landraces (0.95) with a tendency of the cultivars to have more elongated capsules as indicated by the range in cultivar index value up to 1.46 . Nevertheless, five landraces had higher capsule index than the mean capsule index of cultivars. Stigma number and capsule index were not correlated with each other or with the other morphological traits.

Mean seed yield and straw yield of cultivars (132.8 and $127.8 \mathrm{~kg} \mathrm{ha}^{-1}$, respectively) were significantly $(P<0.05)$ higher than for landraces $(100.7$ and $\left.76.5 \mathrm{~kg} \mathrm{ha}^{-1}\right)$. Kemerkaya had the highest seed yield among cultivars. Most of the landraces had lower seed yield than the cultivar with the lowest seed yield, Ofis $8\left(110 \mathrm{~kg} \mathrm{ha}^{-1}\right)$. Landraces 3 and 43 had the highest seed yield among landraces; however, their yields were only average when compared to the cultivars. All of the landraces had lower straw yield than the cultivar with lowest straw yield, Tmo2 $\left(109 \mathrm{~kg} \mathrm{ha}^{-1}\right)$. As might be expected, there was high positive correlation between seed yield and straw yield $(r=0.82)$.

Principal component analysis (PCA) of the quantitative traits showed that the first two eigenvectors explained $61.9 \%$ of the morphological variation. A total of $44 \%$ of the variation were explained by PC1 with high positive correlations to straw and seed yields, morphine content, and plant height (Table S3). PC2 explained $17.9 \%$ of variation with high positive correlation to stigma number and capsule index and low negative correlation to straw and seed yields. Euclidean distances of landraces and cultivars were between 0.32 and 52.48 with an average distance of 13.33. The two-dimensional PCA plot showed that, despite the relatively low number of cultivars, their morphological diversity was much higher than that of the landraces. All the cultivars inhabited the upper left of the PCA plot with no overlap between cultivars and landraces (Fig. 1).

Stepwise discriminant analysis was performed using landrace collection location as a grouping variable and all morphological traits as independents. None of the morphological traits made significant contributions to the multivariate discrimination of the eight Turkish provinces.

\section{Population structure}

Analysis of population structure was performed for the 118 individuals using 200 high-quality, reproducible fragments generated by the 13 EST and 33 genomic SSR markers (the out-group $P$. umbonatum was excluded from population structure analysis). Based on $\Delta K$ values and a plot of $\operatorname{Ln}$ (probability of data), the best model for population structure was two subpopulations $(K=2)$. Of the 118 accessions, $110(93 \%)$ were assigned to subpopulations with 33 individuals in subpopulation A and 77 individuals in subpopulation B. Based on an $80 \%$ membership threshold, the remaining eight accessions were considered to be admixed (Fig. S1 and Table S1). The average distance between individuals in the same cluster was calculated as 0.115 for subpopulation $\mathrm{A}$ and 0.133 for subpopulation B. All but one of the cultivars belonged to 


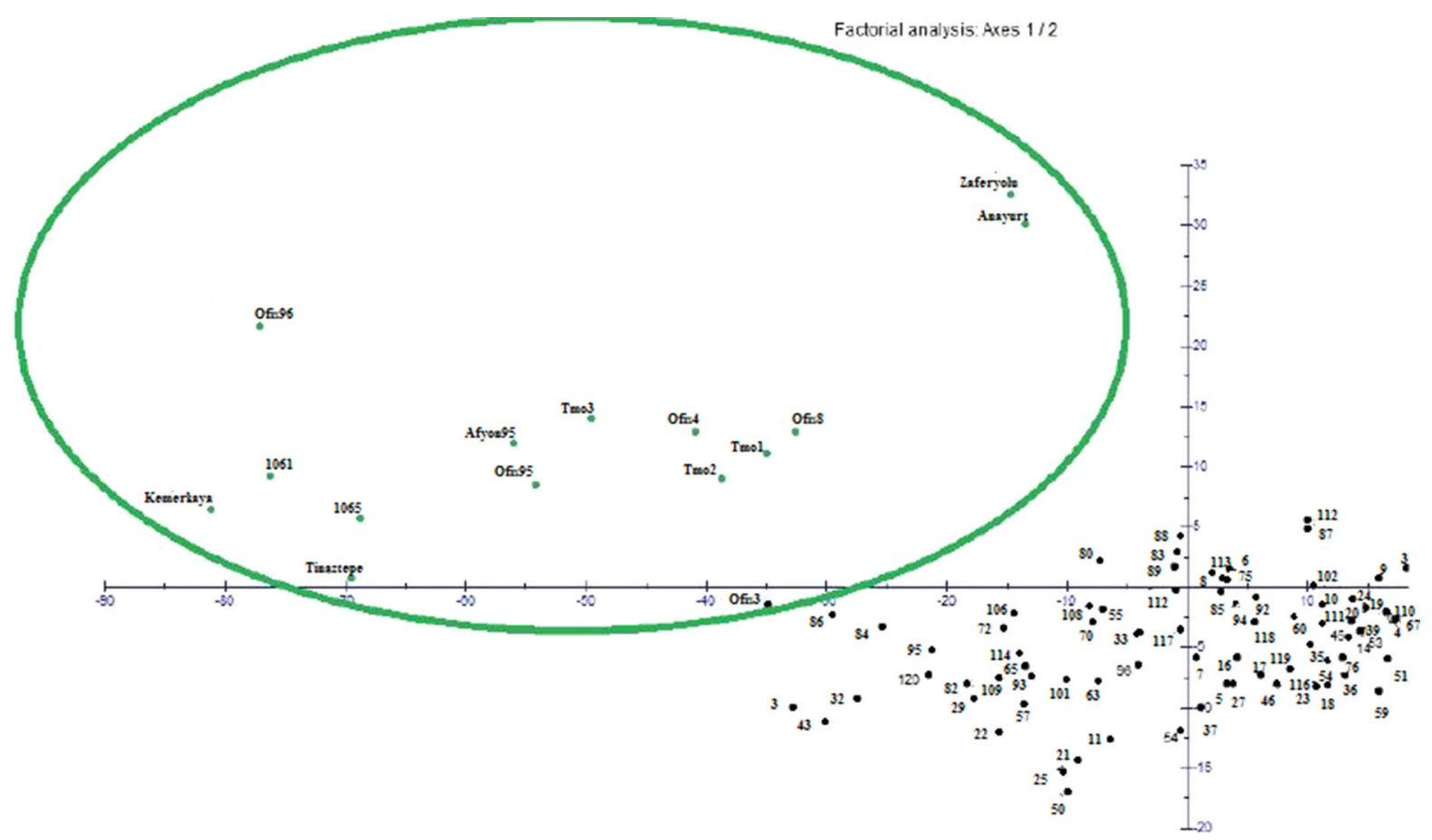

Fig. 1 Principal component analysis (PCA) plot for morphological traits. Green color indicates the cultivars. All of the cultivars clustered together. (Color figure online)

subpopulation A. Tmo3 was the only exception and was found to belong to subpopulation B (Table S1). There was no region-specific clustering of landraces. Stepwise discriminant analysis showed that only straw yield and morphine content made significant contributions to the multivariate discrimination of the three subpopulations (A, B, and admixed) with high correlations for straw yield and morphine content $(r=0.77$ and $r=0.71$, respectively).

Molecular genetic diversity

The EST and genomic SSR marker data were also used to assess the genetic diversity of Turkish opium poppy germplasm. A Mantel test showed a moderate correlation $(r=0.71)$ between the Dice coefficient distance matrices for the two types of markers. Therefore, the EST and genomic SSR were combined and a dendrogram was drawn using the unweighted neighbor-joining algorithm. As expected, a Mantel test showed a strong correlation $(r=0.993)$ between the distance matrix and dendrogram. Dissimilarity between accessions ranged from 0.005 to 0.25 (75\% similarity) with average dissimilarity of 0.11 . The out-group, P. umbonatum clustered separately from $P$. somniferum accessions with a maximum dissimilarity of 0.67 (33\% similarity) to the opium poppy accessions. The $P$. somniferum accessions fell into two clusters (Fig. 2). Cluster 1 contained 84 landraces and dissimilarity in the cluster ranged from 0.015 to 0.20 with an average dissimilarity of 0.075 . Cluster 2 was comprised of 19 landraces and 15 cultivars and dissimilarity in the cluster ranged from 0.006 to 0.19 , with an average dissimilarity of 0.092 . This cluster consisted of two subclusters (subclusters A and B). Cluster 2B contained only named varieties; however, varieties and landraces were intermixed in cluster $2 \mathrm{~A}$. Average genetic diversity of landraces $(0.10)$ was significantly $(P \leq 0.05$ as determined by a Student's $t$ test) higher than average genetic diversity of cultivars (0.07). The hierarchical clustering results revealed no region-specific clustering of Turkish opium poppy accessions.

Genetic diversity of the poppy accessions based on EST and genomic SSR markers was also calculated separately. For EST-SSR markers, genetic diversity ranged from 0 to 0.23 with average diversity of 0.07 . For the genomic SSR markers, the range of genetic diversity was significantly $(P \leq 0.05)$ higher than for 


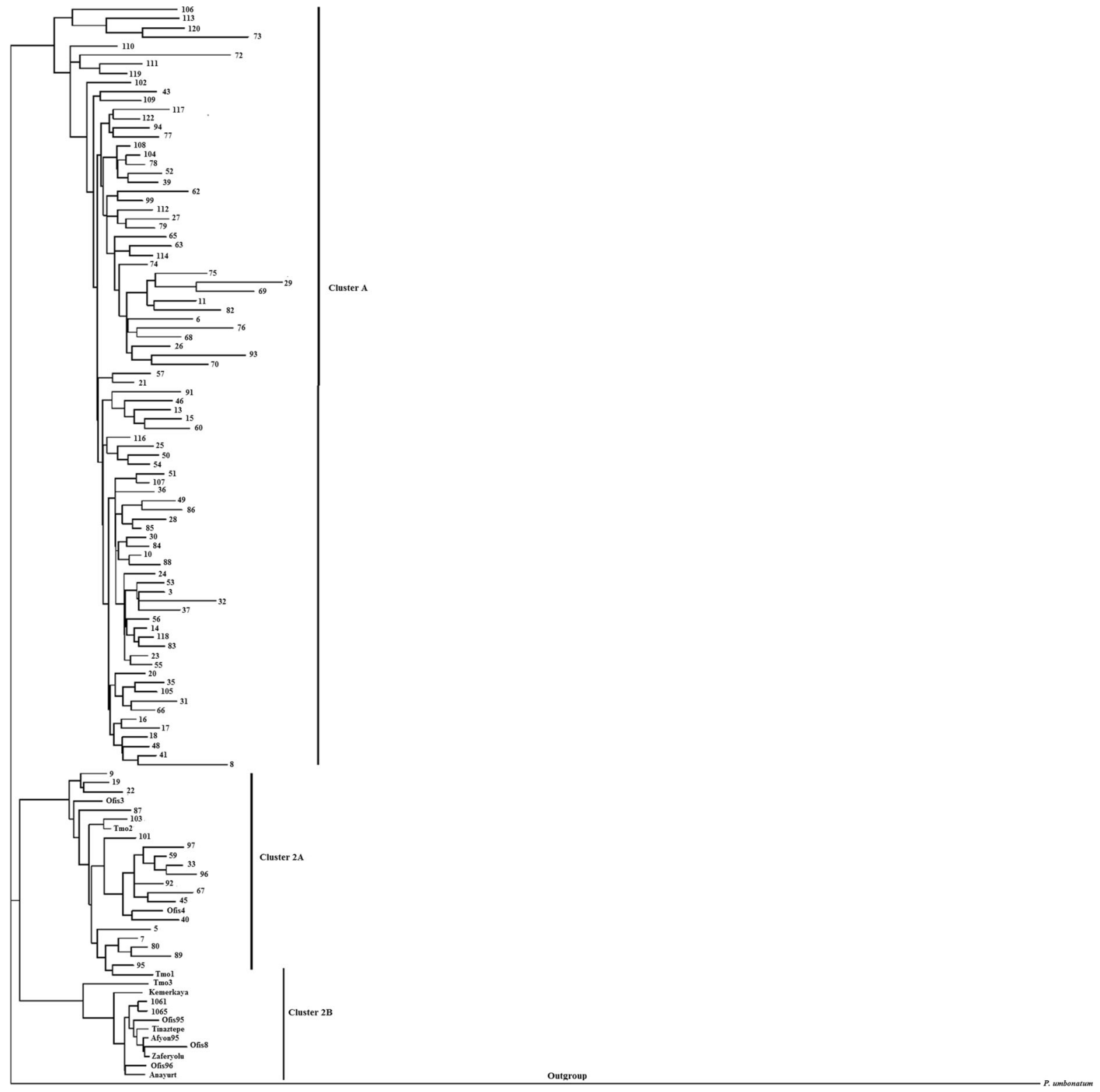

Fig. 2 Unweighted neighbor-joining dendrogram of the poppy accessions constructed with genomic and EST-SSR data

EST-SSRs and ranged from 0 to 0.33 with an average dissimilarity of 0.13 .

\section{Association mapping}

A total of 80 SSR (14 EST-SSR and 66 genomic SSR markers) and 10 AFLP primer combinations were assayed on an AM panel of 95 Turkish opium poppy accessions. Rare loci were deleted $(<10 \%)$ as potentially unreliable. As a result, 282 and 412 loci were generated with the SSR and AFLP markers, respectively. Among these loci, 164 (58 \%) and 367 (89\%) were found to be polymorphic for SSR and AFLP markers, respectively. Thus, 531 polymorphic marker loci were used in AM analysis.

A total of $13,160(6.5 \%)$ SSR and AFLP locus pairs showed significant LD $(P<0.001)$ (Table S4). LD values $\left(r^{2}\right)$ of these locus pairs ranged from 0.03 to 1 with a mean of 0.21 . Most $(82.9 \%)$ of the locus pairs that showed significant LD were AFLP locus pairs 
with a mean of $r^{2}$ of 0.21 (Table S4). AFLP-SSR locus pairs accounted for $14.8 \%$ (1954) of the comparisons with LD and had a mean of $r^{2}$ of 0.18 . Only $2.3 \%$ (300) of the comparisons with LD were SSR locus pairs with a mean $r^{2}$ of 0.25 . Student's $t$ test $(P<0.05)$ showed that the mean LD value $\left(r^{2}\right)$ for the SSR locus pairs was significantly higher than the means for the AFLP and AFLP-SSR locus pairs.

Different AM models [GLM, GLM (Q), GLM (PC), GLM (Q + PC), MLM (K), MLM (Q + K), MLM $(\mathrm{PC}+\mathrm{K}), \operatorname{MLM}(\mathrm{Q}+\mathrm{PC}+\mathrm{K})]$ were compared and used to calculate the proportion of significant results (Table S2). The GLM model corrected with Q-matrix of population structure had highest proportion of significant results among the eight association models $(\pi 1(\%)=9)$ and was used for AM of morphine content and agronomic traits (plant height, stigma number, capsule index, seed yield, and straw yield) in opium poppy (Table S2). It is important to note that the trait means for the association panel were not significantly different from those for the entire set (Student's $t$ test $P<0.05)$.

One SSR and three AFLP loci were significantly associated with morphine content $(P$ value $<0.01)$ (Table 2). SSR marker psgSSR853 was most strongly associated with the trait $(P$ values $=0.002)$ and had an LD value of 0.18. AFLP locus E-ACA + M-CAG-63 had the highest $\mathrm{LD}$ value, 0.32 while the other two AFLP loci (E-ACC + M-CAC-146 and E-AGC + MCTA-138) associated with morphine content had low LD values of 0.10 each.

Five AFLP loci were associated with plant height (Table 2). Among these, AFLP locus E-ACC + MCAG-215 was the most significant $(P$ value $=0.0001)$ with a LD value of 0.19 . The other AFLP loci had similar levels of statistical significance $(P$ values ranging from 0.002 to 0.008 ) and had $\mathrm{LD}$ values ranging from 0.10 to 0.13 .
Table 2 AFLP and SSR markers associated with morphine content and agronomic traits (plant height, stigma number, capsule index, seed yield, and straw yield) in opium poppy

a Markers associated with morphine content and agronomic traits. PsgSSR markers were designed from genomic sequences of opium poppy (Celik et al. 2014). EST-SSR markers were designed from EST sequences of opium poppy (Selale et al. 2013). AFLP markers were named with primer combination and fragment size (bp)

\begin{tabular}{|c|c|c|c|c|}
\hline Trait & Marker $^{\mathrm{a}}$ & Marker type & $P$ value & LD value $\left(r^{2}\right)$ \\
\hline Morphine content $(\%)$ & psgSSR853 & Genomic SSR & 0.002 & 0.18 \\
\hline Morphine content $(\%)$ & E-ACA + M-CAG-63 & AFLP & 0.004 & 0.32 \\
\hline Morphine content $(\%)$ & $\mathrm{E}-\mathrm{ACC}+\mathrm{M}-\mathrm{CAC}-146$ & AFLP & 0.009 & 0.10 \\
\hline Morphine content (\%) & E-AGC + M-CTA-138 & AFLP & 0.005 & 0.10 \\
\hline Plant height $(\mathrm{cm})$ & $\mathrm{E}-\mathrm{ACC}+\mathrm{M}-\mathrm{CAG}-215$ & AFLP & 0.0001 & 0.19 \\
\hline Plant height (cm) & E-AAC + M-CTC-84 & AFLP & 0.008 & 0.13 \\
\hline Plant height $(\mathrm{cm})$ & $\mathrm{E}-\mathrm{ACC}+\mathrm{M}-\mathrm{CAC}-134$ & AFLP & 0.002 & 0.11 \\
\hline Plant height $(\mathrm{cm})$ & $\mathrm{E}-\mathrm{ACC}+\mathrm{M}-\mathrm{CAC}-156$ & AFLP & 0.003 & 0.10 \\
\hline Plant height $(\mathrm{cm})$ & E-ACC + M-CAG-96 & AFLP & 0.008 & 0.10 \\
\hline Stigma number & psgSSR910 & Genomic SSR & 0.008 & 0.14 \\
\hline Stigma number & $\mathrm{E}-\mathrm{ACA}+\mathrm{M}-\mathrm{CAG}-103$ & AFLP & 0.006 & 0.35 \\
\hline Stigma number & $\mathrm{E}-\mathrm{ACC}+\mathrm{M}-\mathrm{CAG}-124$ & AFLP & 0.004 & 0.15 \\
\hline Stigma number & $\mathrm{E}-\mathrm{ACC}+\mathrm{M}-\mathrm{CAG}-153$ & AFLP & 0.006 & 0.10 \\
\hline Stigma number & E-AGG + M-CAT-195 & AFLP & 0.004 & 0.10 \\
\hline Capsule index & psgSSR484 & Genomic SSR & 0.003 & 0.20 \\
\hline Capsule index & psgSSR849 & Genomic SSR & 0.00006 & 0.17 \\
\hline Capsule index & EST-SSR23 & EST-SSR & 0.001 & 0.13 \\
\hline Capsule index & E-ACG + M-CAA-109 & AFLP & 0.007 & 0.08 \\
\hline Seed yield $\left(\mathrm{kg} \mathrm{ha}^{-1}\right)$ & E-AAC + M-CTC-96 & AFLP & 0.004 & 0.15 \\
\hline Seed yield $\left(\mathrm{kg} \mathrm{ha}^{-1}\right)$ & E-AAC + M-CTC-107 & AFLP & 0.005 & 0.14 \\
\hline Seed yield $\left(\mathrm{kg} \mathrm{ha}^{-1}\right)$ & E-AGC + M-CTA-166 & AFLP & 0.008 & 0.10 \\
\hline Straw yield $\left(\mathrm{kg} \mathrm{ha}^{-1}\right)$ & $\mathrm{E}-\mathrm{ACC}+\mathrm{M}-\mathrm{CAG}-153$ & AFLP & 0.002 & 0.13 \\
\hline Straw yield $\left(\mathrm{kg} \mathrm{ha}^{-1}\right)$ & $\mathrm{E}-\mathrm{AGG}+\mathrm{M}-\mathrm{CAT}-213$ & AFLP & 0.004 & 0.10 \\
\hline Straw yield $\left(\mathrm{kg} \mathrm{ha}^{-1}\right)$ & psgSSR909 & Genomic SSR & 0.004 & 0.16 \\
\hline Straw yield $\left(\mathrm{kg} \mathrm{ha}^{-1}\right)$ & psgSSR910 & Genomic SSR & 0.005 & 0.16 \\
\hline
\end{tabular}


One SSR marker and four AFLP fragments generated from three AFLP primer combinations were significantly associated with stigma number (Table 2). PsSSR910 had a LD value of 0.14. AFLP locus E-ACA + M-CAG-103 had the highest LD value, 0.35 , while the other three AFLP loci had LD values ranging from 0.10 to 0.15 .

Three SSR markers and one AFLP locus were significantly associated with the capsule index trait (Table 2). SSR marker psgSSR849 had the highest significance level $(P$ value $=0.00006)$ with a $L D$ value of 0.17. PsgSSR484 had the highest LD value, 0.20. The other two markers had LD values of 0.13 and 0.08 .

A total of three AFLP loci generated by two AFLP primer combinations were significantly associated with seed yields (Table 2). LD values of these loci were $0.15,0.14$, and 0.10 for E-AAC + M-CTC-96, $\mathrm{E}-\mathrm{AAC}+\mathrm{M}-\mathrm{CTC}-107$, and E-AGC + M-CTA-166, respectively. Two AFLP and two SSR markers were significantly associated with straw yield. $\mathrm{LD}$ values of these loci were 0.13 and 0.10 for E-ACC + M-CAG153 and E-AGG + M-CAT-213, respectively. The SSR markers (psgSSR909 and psgSSR909) had slightly higher LD values of 0.16 each.

\section{Discussion}

\section{Morphological trait diversity}

Opium poppy breeding is focused on a few morphological traits including alkaloid content, and seed and straw yields. Morphine is the main narcotic alkaloid of opium poppy and is in high demand (Yadav et al. 2006). Mean morphine content of the Turkish cultivars was nearly twofold higher than landraces. Cultivars also had more variation in morphine content $(0.80 \%$ variation in the range) than landraces $(0.56 \%)$ (Table 1$)$. Gumuscu and Arslan (1999) analyzed morphine content of 20 opium poppy breeding materials from seven countries including Turkey and reported that mean morphine content was $0.65 \%$ with $0.45 \%$ range variation for winter planting and $0.48 \%$ with $0.43 \%$ variation for spring planting. Thus, the cultivars examined in our study showed higher average morphine content with more range variation than those studied by Gumuscu and Arslan (1999).

Mean morphine content of the landraces examined in this work $(0.43 \%)$ was similar to that reported for
353 Turkish accessions which averaged $0.47 \%$ (Arslan et al. 2000). Gumuscu et al. (2008) also found similar morphine levels in 99 Turkish opium poppy genotypes with a mean of $0.48 \%$. The Turkish landraces analyzed in the current work had higher mean morphine content than 115 Indian opium poppy genotypes (mean of $0.23 \%$ ) (Prajapati et al. 2002). The Turkish landraces $(\mathrm{CV}=21 \%)$ also had a slightly higher coefficient of variation than 122 Indian genotypes $(\mathrm{CV}=17 \%$ ) (Shukla et al. 2010). The moderate level of variation for morphine content in the landraces analyzed in this study indicated that this population can be used as an AM panel to find genes controlling morphine synthesis. Although these landraces generally had low breeding potential for morphine content improvement, the top five landraces (genotypes 116, 85, 117, 101, and 46) exceeded $0.60 \%$ morphine and might be useful in breeding.

Cultivars with a mean height of $117.5 \mathrm{~cm}$ were much taller than the breeding material studied by Gumuscu and Arslan (1999) which had a mean height of $76.9 \mathrm{~cm}$. The Turkish landraces examined in this work tended to be shorter than the cultivars. Mean plant height of the landraces $(101.7 \mathrm{~cm})$ was similar to that a world collection containing 404 opium poppy accessions; however, the world collection had a fivefold higher coefficient of variation (25\%) (Brezinová et al. 2009). Singh et al. (2004) showed that plants with medium height and more leaves were more efficient opium producers and may have increased opium latex. In addition, opium poppy cultivars with medium height are more resistant to lodging and make straw harvesting easier. Thus, the opium poppy germplasm used in this study could be good source of alleles for reduced plant height in opium poppy cultivars.

The plant germplasm analyzed in this study had lower mean stigma number than found in previous work, 4.5 versus 11.2 stigmas per flower (Gumuscu and Arslan 1999). These results indicate that the landraces in this study are not good material for improvement of stigma number. Bhandari (1990) suggested that landraces with more stigmas should be selected for morphine content improvement in opium poppy breeding and it was later shown that stigma number is strongly correlated with morphine content (Trivedi et al. 2006). However, no correlation was seen in the current work.

Mean capsule index of the Turkish poppy landraces was 0.95 , indicating almost perfectly globular capsules. This value was lower than that for the world 
collection (mean of 1.19) (Brezinová et al. 2009). The population used in this study had considerable variation for capsule index $(\mathrm{CV}=9 \%)$, similar to that observed in the world collection of opium poppy containing 404 genotypes $(\mathrm{CV}=10.2 \%)$ (Brezinová et al. 2009). Because seed and morphine yields are reported to be maximized in globular capsules (Brezinová et al. 2009), Turkish opium poppy landraces are a good source of alleles toward this breeding goal. In addition, this material shows sufficient diversity to be used in AM to understand the genetic basis of capsule shape.

Seed and straw yields are two of the most important traits in opium poppy breeding. Seed yield for the landraces $\left(100.7 \mathrm{~kg} \mathrm{ha}^{-} 1\right)$ was much lower than for the TMO and AARI cultivars $\left(132.8 \mathrm{~kg} \mathrm{ha}^{-1}\right)$, but was similar to the mean yield obtained from selected breeding materials from seven countries including Turkey (approximately $101 \mathrm{~kg} \mathrm{ha}^{-1}$ ) (Gumuscu and Arslan 1999). The breeding lines had higher average straw yield $\left(92.1 \mathrm{~kg} \mathrm{ha}^{-1}\right)$ than the Turkish landraces (76.5 $\mathrm{kg} \mathrm{ha}^{-1}$ ), but straw yield was lower than the cultivars $\left(127.8 \mathrm{~kg} \mathrm{ha}^{-1}\right)$ analyzed in this study. These results indicate that the TMO and AARI cultivars were more improved than the opium poppy breeding materials analyzed by Gumuscu and Arslan 1999. Although there was diversity for seed and straw yields in the landraces (67 and $52 \mathrm{~kg} \mathrm{ha}^{-1}$ range diversity for seed and straw yields, respectively), none of the landraces appeared to be suitable as parental material for improvement of these two traits.

The PCA based on the morphological traits of the poppy accessions indicated complete separation of the cultivars with no overlap with landraces. As might be expected, most of the variance in the first axis was explained by morphine content and yield traits. Surprisingly, the cultivars did not show reduced morphological variability compared to the landraces. At first glance, the results from morphological analysis suggest that Turkish landraces may not be the best source of alleles for opium poppy improvement due to their overall poor morphine content and yield as compared to current Turkish cultivars. However, it must be noted that Turkish landraces had similar breeding potential to the world collection in terms of means and variability for plant height and capsule index and for morphine content when compared to Indian landraces (Shukla et al. 2010). The low breeding potential of the Turkish landraces for stigma number, seed yield, and straw yield indicates that germplasm from other countries may prove useful in improving these particular traits in Turkish cultivars.

Population structure and molecular genetic diversity

Structure analysis indicated a low level of molecular genetic diversity, an expected result given previous analyses using the same EST (Selale et al. 2013) and genomic SSR (Celik et al. 2014) markers. As with the morphological traits, molecular genetic analysis indicated separate clustering of cultivars and landraces. Moreover, the subpopulations detected by population structure analysis coincided with the clustering results of the neighbor-joining dendrogram. All of the accessions in subpopulation A were in cluster 2 of the dendrogram. In addition, all of the accessions in subpopulation B were in cluster 1 of the dendrogram. All admixed individuals except for Tmo3 were found in cluster 1 in the neighbor-joining dendrogram.

Both straw yield and morphine content made significant contributions to multivariate discrimination of the three subpopulations (A, B, and admixed) with high correlations. This was expected because subpopulation A contained most of the cultivars which had higher straw yield and morphine content than the landraces.

When genetic diversity was compared across the accessions, landraces (0.10) were found to have higher average genetic diversity than cultivars (0.07). These results indicate that breeding has caused a slight bottleneck in the crop. Given the limited amount of molecular genetic variability available in landraces, the best approach to developing diversity in Turkish material seems to be introduction of genetic material from other countries.

\section{Association mapping}

Mating system, population type, and genomic region affect the proportion of marker pairs showing significant LD (Ranc et al. 2012). Opium poppy is selfpollinated with a small proportion of outcrossing. In addition, the opium poppy germplasm studied in the present study had low genetic diversity. Thus, it was expected that only a low proportion of marker pairs would have significant LD. In comparison, SSR markers in upland cotton, which has a similar mating 
system as opium poppy, had slightly higher LD (11 and $9.4 \%$ ) than the present study $(6.5 \%$ ) (Abdurakhmonov et al. 2008; Qin et al. 2015, respectively). This difference was probably due to population size because the upland cotton studies used much larger populations (241 and 286 individuals). Thus, the smaller population and low diversity of the opium poppy germplasm analyzed in the present study might lead to an underestimation of opium poppy LD. LD can also be due to marker linkage but this could not be confirmed because the SSR and AFLP loci used in this study are not mapped in the opium poppy genome. LD can also be due to selection and relatedness of opium poppy landraces which can lead false-positive associations between markers and traits (Pritchard et al. 2000b; Stich et al. 2005). To avoid these false-positive associations, AM analysis was corrected using the Q-matrix of population structure generated by STRUCTURE software.

The mean LD values $\left(r^{2}\right)$ of the SSR locus pairs were higher than the means for the AFLP and AFLP-SSR locus pairs due to the different source of the two marker systems. The SSR markers used in the present study were designed from EST and genomic sequences with limited coverage in the opium poppy genome: 0.4 and $2.83 \%$ coverage for EST and genomic sequences, respectively (Selale et al. 2013; Celik et al. 2014). In contrast, AFLP markers are random markers with high genome coverage (Jones et al. 2009).

The most economically important trait of opium poppy is morphine content. SSR and AFLP loci associated with this trait had low LD value $\left(r^{2}\right)$. This indicated that each QTL explained a small proportion of the phenotypic variation of morphine content which might be due to dispersion of multiple genes for morphine synthesis in the opium poppy genome. This must be further tested by determining the locations of the markers in the genome and by the addition of more markers. Despite these limitations, these markers are valuable because they can be used to improve the morphine content of opium poppy by 10-32\%.

A total of five SSR and 14 AFLP markers were found to be associated with five agronomic traits in opium poppy. The greater number of AFLP loci associated with the traits compared to SSR loci was due to the higher number of polymorphic fragments and higher variation of AFLP markers than SSR markers. LD values $\left(r^{2}\right)$ of the SSR and AFLP loci ranged from 0.08 to 0.35 . These results indicated that the agronomic traits of opium poppy studied in this study were controlled by loci with minor effect rather than major QTL.

In conclusion, molecular genetic and morphological trait diversity analyses were used to assess the usefulness of Turkish landraces for opium poppy breeding. Overall, the results suggest that Turkish landraces have good sources of alleles for morphine content, plant height, and capsule index traits. However, the introduction of non-Turkish material into breeding programs may be necessary to improve overall molecular genetic diversity and traits such as stigma number, seed yield, and straw yield. In addition, markers associated with QTLs for morphine content provided initial information for marker-assisted selection in opium poppy breeding.

Acknowledgments This study was supported by The Scientific and Technological Research Council of Turkey (TUBITAK) Project No: 1090797. We thank Amy Frary for review of the manuscript.

Author contributions IC performed molecular characterization, data analysis, and manuscript preparation. $\mathrm{HC}, \mathrm{AK}$, and FCK performed morphological characterization. SD involved in experimental design and manuscript preparation. AF performed data analysis and manuscript preparation.

\section{Compliance with ethical standards}

Conflict of interest The authors declare that they have no conflict of interest.

\section{References}

Abdurakhmonov IY, Kohel RJ, Yu JZ, Pepper AE, Abdullaev AA, Kushanov FN, Abdukarimov A (2008) Molecular diversity and association mapping of fiber quality traits in exotic G. hirsutum L. germplasm. Genomics 92(6):478-487. doi: 10.1016/j.ygeno.2008.07.013

Acharya HS, Sharma V (2009) Molecular characterization of opium poppy (Papaver somniferum) germplasm. Am J Infect Dis 5:148-153

Achleitner A, Tinker NA, Zechner E, Buerstmayr H (2008) Genetic diversity among oat varieties of worldwide origin and associations of AFLP markers with quantitative traits. Theor Appl Genet 117(7):1041-1053. doi:10.1007/s00122008-0843-y

Akhatar J, Banga SS (2015) Genome-wide association mapping for grain yield components and root traits in Brassica juncea (L.) Czern \& Coss. Mol Breed 35:48. doi:10.1007/ s11032-015-0230-8

Arslan N, Buyukgocmen R, Gumuscu A (2000) Türk haşhaş populasyonlarının yağ ve morfin muhtevaları. J Field Crops Central Res Inst 9:1-2 
Bhandari MM (1990) Out-crossing in opium poppy Papaver somniferum L. Euphytica 48:167-169. doi:10.1007/BF00037196

Bradbury PJ, Zhang Z, Kroon DE, Casstevens TM, Ramdoss Y, Buckler ES (2007) TASSEL: software for association mapping of complex traits in diverse samples. Bioinformatics 23(19):2633-2635. doi:10.1093/bioinformatics/ btm 308

Brezinová B, Macák M, Eftimová J (2009) The morphological diversity of selected traits of world collection of poppy genotypes (genus Papaver). J Cent Eur Agric 10:183-192

Celik I, Gultekin V, Allmer J, Doganlar S, Frary A (2014) Development of genomic simple sequence repeat markers in opium poppy by next-generation sequencing. Mol Breed 34:323-334. doi:10.1007/s11032-014-0036-0

Collard BCY, Jahufer MZZ, Brouwer JB, Pang ECK (2005) An introduction to markers, quantitative trait loci (QTL) mapping and marker-assisted selection for crop improvement: the basic concepts. Euphytica 142:169-196. doi:10. 1007/s10681-005-1681-5

Dent AE, Bridgett MV (2012) Structure harvester: a website and program for visualizing STRUCTURE output and implementing the Evanno method. Conserv Genet Resour 4:359-361. doi:10.1007/s12686-011-9548-7

Dittbrenner A, Lohwasser U, Mock HP, Borner A (2008) Molecular and phytochemical studies of Papaver somniferum in the context of infraspecific classification. Acta Hortic 799:81-88. doi:10.17660/ActaHortic.799.9

Doyle JJ, Doyle JE (1990) Isolation of plant DNA from fresh tissue. Focus 12:13-15

Eckert AJ, Wegrzyn JL, Cumbie WP, Goldfarb B, Huber DA, Tolstikov V, Fiehn O, Neale DB (2012) Association genetics of the loblolly pine (Pinus taeda, Pinaceae) metabolome. New Phytol 193:890-902

Facchini PJ, De Luca V (2008) Opium poppy and Madagascar periwinkle: model non-model systems to investigate alkaloid biosynthesis in plants. Plant $\mathrm{J}$ Cell Mol Biol 54:763-784. doi:10.1111/j.1365-313X.2008.03438.X

Gómez G, Álvarez MF, Mosquera T (2011) Association mapping, a method to detect quantitative trait loci: statistical bases. Agronomía Colombiana 29(3):367-376

Gumuscu A, Arslan N (1999) Comparing yield and yield components of some selected poppy (Papaver somniferum L.) lines. Turk J Agric For 4:991-997

Gumuscu A, Arslan N (2008) Researches on heterosis on yield and yield components of some poppy hybrid lines. J Agric Sci 14:365-373

Gumuscu A, Arslan N, Sarihan EO (2008) Evaluation of selected poppy (Papaver somniferum L.) lines by their morphine and other alkaloids contents. Eur Food Res Technol 226:1213-1220. doi:10.1007/s00217-007-0739-0

Jones N, Ougham H, Thomas H, Pašakinskienè I (2009) Markers and mapping revisited: finding your gene. New Phytol 183(4):935-966. doi:10.1111/j.1469-8137.2009.02933.x

Norusis MJ (2010) PASW statistics 18 advanced statistical procedures. Prentice Hall Press, Englewood Cliffs

Parmaksiz I, Ozcan S (2011) Morphological, chemical and molecular analyses of Turkish Papaver accessions (Sect. Oxytona). Turk J Bot 35:1-16. doi:10.3906/bot-1003 $-39$

Patra NK, Ram RS, Chauhan SP, Singh AK (1992) Quantitative studies on the mating system of opium poppy (Papaver somniferum L.). Theor Appl Genet 84:299-302. doi:10. 1007/BF00229486

Perrier X, Jacquemoud-Collet JP (2006) DARwin software. http://darwin.cirad.fr/darwin

Prajapati S, Bajpai S, Singh D, Luthra R, Gupta MM, Kumar S (2002) Alkaloid profiles of the Indian land races of the opium poppy Papaver somniferum L. Genet Resour Crop Evol 49:183-188. doi:10.1023/A:1014763412736

Price AL, Patterson NJ, Plenge RM, Weinblatt ME, Shadick NA, Reich D (2006) Principal components analysis corrects for stratification in genome-wide association studies. Nat Genet 38:904-909. doi:10.1038/ng1847

Pritchard JK, Stephens M, Donnelly P (2000a) Inference of population structure using multilocus genotype data. Genetics 155:945-959

Pritchard JK, Stephens M, Rosenberg NA, Donnelly P (2000b) Association mapping in structured populations. Am J Hum Genet 67:170-181. doi:10.1086/302959

Qin H, Chen M, Yi X, Bie S, Zhang C, Zhang Y, Lan J, Meng Y, Yuan Y, Jiao C (2015) Identification of associated SSR markers for yield component and fiber quality traits based on frame map and upland cotton collections. PloS ONE 10(1). doi:10.1371/journal.pone.0118073

Ranc N, Muños S, Xu J, Le Paslier MC, Chauveau A, Bounon R, Rolland S, Bouchet JP, Brunel D, Causse M (2012) Genome-wide association mapping in tomato (Solanum lycopersicum) is possible using genome admixture of Solanum lycopersicum var. cerasiforme. G3 Genes Genom Genet 2(8):853-864. doi:10.1534/g3.112.002667

Saunders JA, Pedroni MJ, Penrose LDJ, Fist AJ (2001) AFLP analysis of opium poppy. Crop Sci 41:1596-1601. doi:10. 2135/cropsci2001.4151596x

Selale H, Celik I, Gultekin V, Allmer J, Doganlar S, Frary A (2013) Development of EST-SSR markers for diversity and breeding studies in opium poppy (Papaver somniferum L.). Plant Breed 132:344-351. doi:10.1111/pbr.12059

Semagn K, Bjørnstad Å, Xu Y (2010) The genetic dissection of quantitative traits in crops. Electron $\mathrm{J}$ Biotechn 13(5): 16-17. doi:10.2225/vol13-issue5-fulltext

Shukla S, Yadav HK, Rastogi A, Mishra BK, Sant Singh P (2010) Alkaloid diversity in relation to breeding for specific alkaloids in opium poppy (Papaver somniferum L.). Czech J Genet Plant Breed 46:164-169

Singh SP, Shukla S, Yadav HK (2004) Genetic studies and their implication to breed desired plant type in opium poppy, Papaver somniferum L. Genetika 36:69-81. doi:10.2298/ GENSR0401069S

Stich B, Melchinger AE, Frisch M, Maurer HP, Heckenberger M, Reif JC (2005) Linkage disequilibrium in European elite maize germplasm investigated with SSRs. Theor Appl Genet 111(4):723-730. doi:10.1007/s00122-005-2057-X

Storey JD (2002) A direct approach to false discovery rates. J R Stat Soc Ser B 64:479-498. doi:10.1111/1467-9868.00346

Storey JD, Tibshirani R (2003) statistical significance for genome-wide experiments. Proc Natl Acad Sci USA 100:9440-9445. doi:10.1073/pnas. 1530509100

Tétényi P (1997) Opium poppy (Papaver somniferum) botany and horticulture. Hortic Rev 19:373-408. doi:10.1002/ 9780470650622.ch7

Trivedi M, Tiwari RK, Dhawan OP (2006) Genetic parameters and correlations of collar rot resistance with important 
biochemical and yield traits in opium poppy (Papaver somniferum L.). J Appl Genet 47:29-38. doi:10.1007/ BF03194596

Turkish Soil Product Office (2009) Opium poppy report. Turkish Soil Production Office, Ankara

Turkish Soil Product Office (2014) Opium poppy report. Turkish Soil Production Office, Ankara

Wang ML, Sukumaran S, Barkley NA, Chen Z, Chen CY, Guo B, Pittman RN, Stalker HT, Holbrook CC, Pederson GA, Yu J (2011) Population structure and marker-trait association analysis of the US peanut (Arachis hypogaea L.) mini-core collection. Theor Appl Genet 123(8):1307-1317. doi:10. 1007/s00122-011-1668-7

Weber AL, Briggs WH, Rucker J, Baltazar BM, Sánchez-Gonzalez JDJ, Feng P, Bucler ES, Doebley J (2008) The genetic architecture of complex traits in teosinte (Zea mays ssp. parviglumis): new evidence from association mapping. Genetics 180(2):1221-1232. doi:10.1534/genetics.108.090134
Wei W, Zhang Y, Lü H, Li D, Wang L, Zhang X (2013) Association analysis for quality traits in a diverse panel of Chinese sesame (Sesamum indicum L.) germplasm. J Integr Plant Biol 55(8):745-758. doi:10.1111/jipb.12049

Yadav HK, Shukla S, Singh SP (2006) Genetic variability and interrelationship among opium and its alkaloids in opium poppy (Papaver somniferum L.). Euphytica 150:207-214. doi:10.1007/s10681-006-9111-x

Yu J, Pressoir G, Briggs WH, Bi IV, Yamasaki M, Doebley JF, McMullen MD, Gaut BS, Holland JB, Kresovich S, Buckler ES (2006) A unified mixed-model method for association mapping accounting for multiple levels of relatedness. Nat Genet 38:203-208. doi:10.1038/ng1702

Zhu C, Gore M, Buckler ES, Yu J (2008) Status and prospects of association mapping in plants. Plant Genome 1(1):5-20. doi:10.3835/plantgenome2008.02.0089 